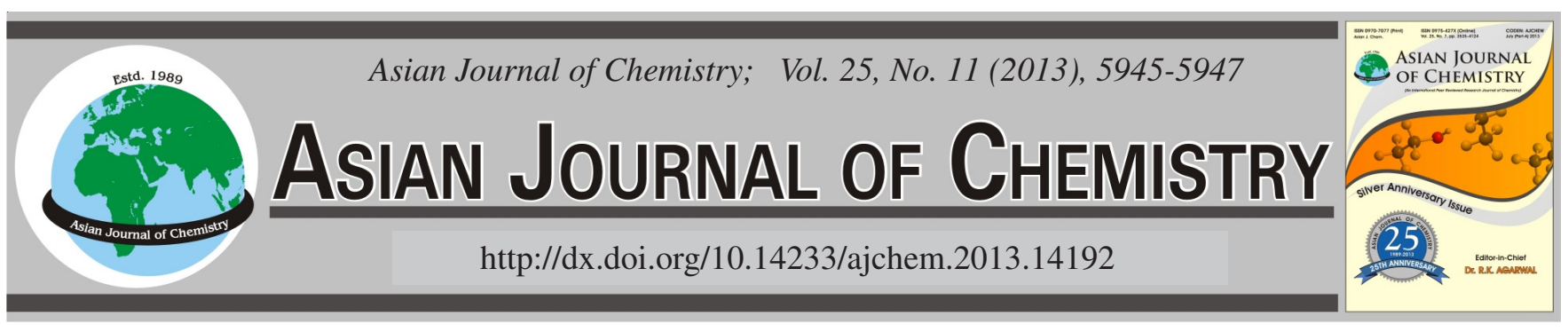

\title{
Fabrication of Porous Thin Film Core for Micro-Fluxgate by Using Anodic Aluminum Oxide Templates
}

\author{
Hui Lv ${ }^{1,2, *}$ and SHIBIN LiU ${ }^{1}$
}

${ }^{1}$ School of Electronics and Information, Northwestern Polytechnical University, Xi'an, P.R. China

${ }^{2}$ Electrical Engineering and Automation institute, Henan Polytechnic University, Jiaozuo, P.R. China

*Corresponding author: E-mail: 1vhui007@hpu.edu.cn

(Received: 11 June 2012;

Accepted: 20 April 2013)

\begin{abstract}
Porous thin film core is conducive to impelling the micro-fluxgate toward the direction of low power consumption and high sensitivity. In this experiment, anodic aluminum oxide templates were obtained by two-step anodization process. We could obtain a copper template by two-step replication of the anodic aluminum oxide template. Furthermore, porous Fe-Ni thin film was fabricated by magnetron sputtering on the copper template. The morphology of the porous film complies with the anticipation. The characteristic of the pores can be changed by adjusting the experimental parameters.
\end{abstract}

Key Words: Nanopore, Thin film core, Two-step replication.

\section{INTRODUCTION}

Fluxgate is a kind of magnetic sensors used in vectorial magnetic measurement with excellent thermal stability ${ }^{1}$. Traditional fluxgate sensors have high sensitivity but a bulky volume. In recent decades, micro fluxgate sensors developed quickly with the application of MEMS(Micro-Electro-Mechanical Systems) technology ${ }^{2}$. The recent trends were decreasing of the sensor size, power consumption and price and, on the other hand, increasing of the precision in the large range of measured fields ${ }^{3}$. The fabrication of high quality ferromagnetic core allows fluxgate to maintain high performance in spite of size reduction.

For soft magnetic properties of fluxgate core, how to get a saturation magnetization as low as possible while ensuring high magnetic permeability and low magnetic coercive force is a basic requirement. In other word, we focus on how to make a core excited by small current can reach saturation quickly ${ }^{4}$. Silicon-based Fe-Ni thin film core is consistent with the requirements of micro-fluxgate core ${ }^{5}$. Furthermore, we have found that porous structure of thin film core is more conducive to impelling the micro-fluxgate toward the direction of low power consumption and high sensitivity ${ }^{6}$.

In this work, we reported fabrication process of porous thin film core for micro-fluxgate. A silicon-based porous $\mathrm{Fe}-\mathrm{Ni}$ thin film was fabricated by magnetron sputtering on copper template obtained by two-step replication of anodic aluminum oxide template. The morphology of the porous film complied with the anticipation.

\section{EXPERIMENTAL}

The aluminum sheets with a purity of $99.9 \%$ were used in this work. Before anodizing, the samples were firstly vacuum-annealed at $500{ }^{\circ} \mathrm{C}$ for $4 \mathrm{~h}$ to remove mechanical stress and to recrystallize the samples. The natural oxide film on the aluminum sheet was degreased in $2.0 \mathrm{~mol} / \mathrm{L}$ sodium hydroxide $(\mathrm{NaOH})$ at $50^{\circ} \mathrm{C}$ for $5 \mathrm{~min}$ and washed in deionized water. Then, the sheets were put into $1.5 \mathrm{~mol} / \mathrm{L}$ nitric acid for $3 \mathrm{~min}$ to counteract remnant lye. Subsequently, the samples were electropolished for $3 \mathrm{~min}$ in a 1:5 (volume ratio) mixture of perchloric acid and absolute ethanol, with a current density of $15 \mathrm{~A} / \mathrm{dm}^{2}$. Magnetic stirring was applied in order to reduce the surface roughness. The samples were thoroughly rinsed with distilled water. The surface of the well-polished aluminum sheet was shiny and mirror-like.

The ordered porous alumina membrane was prepared by two-step anodization process according to previous reports ${ }^{7-9}$. The first anodization process was done inside the anodization cell by applying a constant voltage of $40 \mathrm{~V}$ and using a 0.3 $\mathrm{moL} / \mathrm{L}$ oxalic acid solution. The aluminum sheet acted as the anode and a graphite plate as the cathode. The change of current is shown in Fig. 1. The anodization temperature was kept constant at $4{ }^{\circ} \mathrm{C}$ in order to get lower growth rate of the pores, so as to be favorable for self-organization. After the first anodization of $4 \mathrm{~h}$, the anodic aluminum oxide was removed by a wet chemical etching in a mixture of phosphoric acid $\left(6\right.$ wt. \%) and chromic acid $\left(1.8\right.$ wt. \%) at $60^{\circ} \mathrm{C}$. Then the 


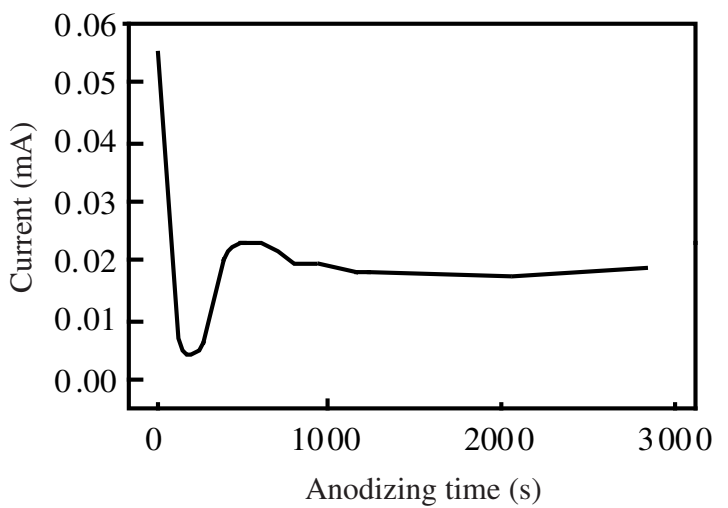

Fig. 1. Curve of the anodization current

samples were anodized again for $1 \mathrm{~h}$ under the same conditions as the first anodization process as mentioned above. Highly ordered anodic aluminum oxide template was formed.

At the end of the second process of anodization, the voltage was progressively stepped down from 40-2 $\mathrm{V}$ at the rate of $2 \mathrm{~V} / \mathrm{min}$ (Fig. 2). Because the thickness of the barrier layer is proportional to the applied voltage, the barrier layer was almost completely removed when the voltage reached 2 $\mathrm{V}^{10,11}$. At last, anodic aluminum oxide membrane was separated from $\mathrm{Al}$ substrate by reversing the applied voltage of anodization to a negative bias. The remain barrier layer was removed in phosphoric acid $(5 \mathrm{wt} . \%)$ at $30^{\circ} \mathrm{C}$. We could obtain the anodic aluminum oxide template with through holes. Typical pore diameter and wall thickness values obtained with an etching treatment of $0.5 \mathrm{~h}$ are $c a .80$ and $100 \mathrm{~nm}$, respectively. The thickness of templates could reach about $30 \mu \mathrm{m}$.

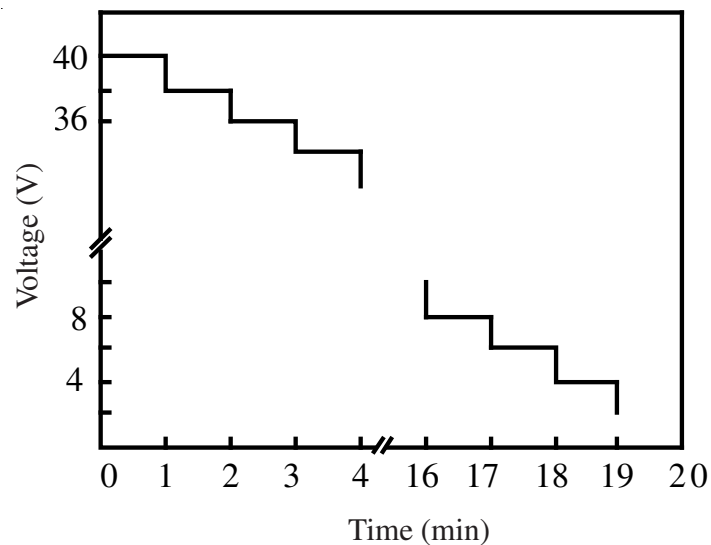

Fig. 2. Stepwise decrease of the applied voltage for removing the barrier layer

Copper film (300 $\mathrm{nm}$ thickness) was prepared on the silicon wafers substrate by magnetron sputtering. The wafers were rectangular of $30 \mathrm{~mm}$ length and $1.5 \mathrm{~mm}$ width. They were cleaned by ultrasonic for $20 \mathrm{~min}$, then rinsed and dried by deionized water and nitrogen gas. The anodic aluminum oxide templates were fixed on copper film. They acted as the cathode and a copper plate as the anode ${ }^{12}$. The deposition was carried out in a $267 \mathrm{~mL}$ Hull cell, with a closed atmosphere under the room temperature. The samples were electroplated for $0.5 \mathrm{~h}$ in a mixture of $\mathrm{CuSO}_{4}(200 \mathrm{~g} / \mathrm{L}), \mathrm{H}_{2} \mathrm{SO}_{4}(60 \mathrm{~g} / \mathrm{L}), \mathrm{NaCl}(100 \mathrm{mg} / \mathrm{L})$ and $\mathrm{AuC}_{6} \mathrm{H}_{5} \mathrm{O}_{7}(4 \mathrm{~mL} / \mathrm{L})$, with a current density of $0.5 \mathrm{~A} / \mathrm{dm}^{2}$.
After electrodeposition, the anodic aluminum oxide templates were removed by immersion in $\mathrm{NaOH}$ solutions ( 2 $\mathrm{moL} / \mathrm{L}$ ) at $25^{\circ} \mathrm{C}$ for $2 \mathrm{~h}$. Then, the samples were thoroughly rinsed with distilled water and subsequently dried in nitrogen. We could obtain a replicated negative type of copper with a nanoscale cylindrical array structure.

The $\mathrm{Ni}_{81} \mathrm{Fe}_{19}$ film was fabricated on the copper template by magnetron sputtering. The process was finished in JGP450 high vacuum multifunctional magnetron sputtering instrument. Film was deposited with pure Ar sputtering gas. Experimental parameters are as follow: Background pressure: $1.5 \times 10^{-3} \mathrm{~Pa}$, sputtering current: $0.26 \mathrm{~A}$, working pressure: $1 \mathrm{~Pa}$, argon gas flow rate: $120 \mathrm{sccm}$, deposition time: $50 \mathrm{~min}$, substrate temperature: $200{ }^{\circ} \mathrm{C}$, the process for the fabrication of the porous thin film is shown in Fig. 3.

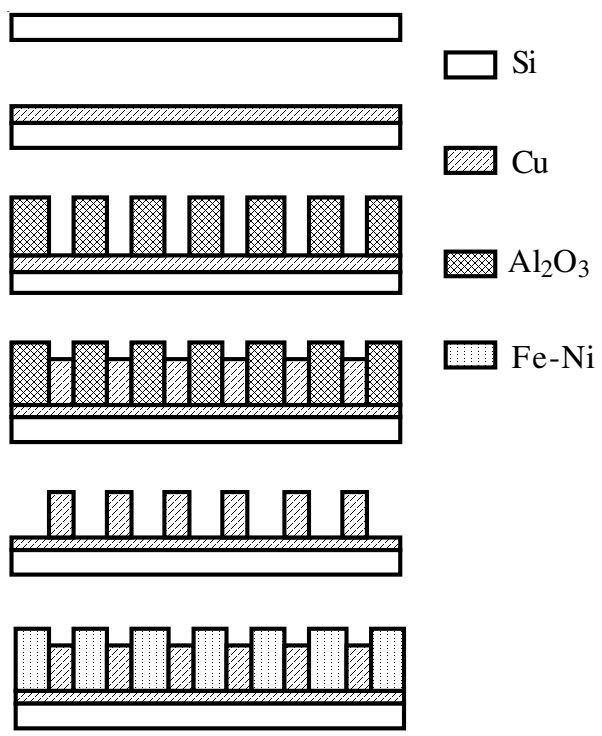

Fig. 3. Schematic diagram of the process for the fabrication of the porous thin film

\section{RESULTS AND DISCUSSION}

By two-step replication of anodic aluminum oxide template, we made nanohole Fe-Ni film with thickness $2 \mu \mathrm{m}$. The morphology and structural properties of Fe-Ni film were characterized by scanning electron microscopy. The SEM image in Fig. 4 clearly shows the typical hollow structure of the nanohole film.

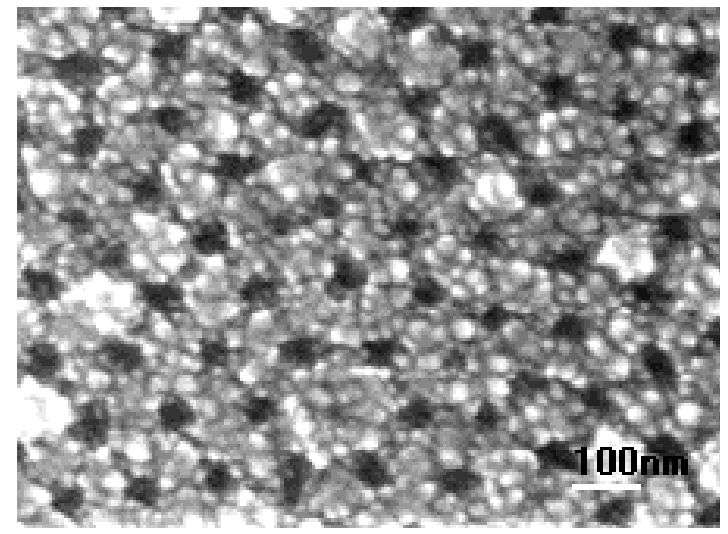

Fig. 4. SEM image of porous thin film 
For SEM observation, the surface of sample was coated with nanoscale particles. These small particles with good dimension and homogeneity were distributed regularly in substrates. They grew up along the cylinder array of copper template. A magnetron sputtering treatment of 20 min could not fill the gap between the cylinders .With more sputtering time, the gap could be filled. Furthermore particles gradually become larger and agglomerate. When sputtering time reached ca. $50 \mathrm{~min}$, size of particles increased dramatically and particles began to grow horizontally. This lateral growth process formed a membrane in which there were many ordered nanoholes. In these holes, copper cylinders of templates were remained. They were not removed because the copper structure could not influence magnetic characteristics of porous $\mathrm{Fe}-\mathrm{Ni}$ film.

\section{Conclusion}

In summary, we have successfully prepared the ordered porous anodic aluminum oxide templates by an efficient two-step anodization process. By means of stepping down the voltage at the end of the second anodization and chemical etching treatment, the barrier layer can be removed. Furthermore, we have obtained a replicated negative type of copper by electrodeposition. On the copper template, The Fe-Ni porous thin film can be fabricated by magnetron sputtering. The density and diameter of the pores comply with the anticipation. The morphology of the film can be changed by adjusting the experimental parameters. By varying the anodization voltage and the concentration of electrolyte, we can control the density and diameter of the nanopores ${ }^{13,14}$. The temperature of etching treatment also affects the morphology of pores remarkably. An etching solution temperature of $30^{\circ} \mathrm{C}$ is identified to be the optimum temperature for the etching step. Time of magnetron sputtering process is also a key part of good morphology and right thickness to the thin film.

\section{ACKNOWLEDGEMENTS}

The project was supported by Specialized Research Fund for the Doctoral Program of Higher Education (No. 20126102110031).

\section{REFERENCES}

1. P. Ripka, IEEE Transc. Magn., 34, 1303 (1998).

2. P. Ripka, Sens. Actuators A, 33, 129 (1992).

3. P. Ripka, Sens. Actuators A, 106, 8 (2003).

4. L. Shibin, Sens. Actuators A, 130, 124 (2006).

5. F.E. Rasmussen, Sens. Actuators A, 92, 242 (2001).

6. T. Veres, Thin Solid Films, 382, 172 (2001).

7. H. Masuda and K. Fukuda, Science, 268, 1466 (1995).

8. H. Chick and J.M. Xu, Mater. Sci. Eng. R, 43, 103 (2004).

9. K.H. Lee, Y.P. Huang and C.C. Wong, Electrochim. Acta, 56, 2394 (2011).

10. L. Zaraska, G.D. Sulka and M. Jaskula, Surf. Coat. Technol., 205, 2432 (2010).

11. Q. Wang, X. Sun, S. Luo, L. Sun, X. Wu and M. Cao, Cryst. Growth Des., 7, 2665 (2007).

12. N.J. Gerein and J.A. Haber, J. Phys. Chem. B, 109, 17372 (2005).

13. W. Lee, R. Ji and U. Gosele, Nature Mater., 105, 741 (2006).

14. G.D. Sulka and K.G. Parkola, Thin Solid Film., 515, 338 (2006). 